\title{
The Fe-Cu Metastable Nano-scale Compound for Enhanced Absorption in the UV-Vis and NIR Ranges
}

\begin{abstract}
ABDUL HAI ALAMI, JEHAD ABED, MEERA ALMHEIRI, and AFRA ALKETBI
This paper investigates the synthesis, microstructural characterization, electrical and optical, and thermal testing of $\mathrm{Fe}-\mathrm{Cu}$ metastable alloy system for selective solar absorption applications. The system is produced by mechanical alloying using high-energy ball milling while monitoring its crystallographic morphology via X-ray diffraction from the initial as-is mixture up to the one produced after 8 hours milling time. The resulting homogeneous, metastable microstructure is examined by scanning electron microscopy and energy dispersive X-ray spectroscopy to verify the sought result of efficient inter-diffusion of elements. Optical spectroscopy results exhibit up to 81 pct enhanced absorption in the UV-Vis-NIR wavelength range with increased milling time from the as-is compound to the one obtained after 8 hours, while the trends of absorptivity curves had clear correlations with microstructural evolution. The impedance measurement of the resulting compound shows an increase in the resistance up to $120 \Omega$, compared with zero for the as-is starting mixture, which is a useful observation for many applications.
\end{abstract}

DOI: $10.1007 / \mathrm{s} 40553-015-0060-\mathrm{y}$

(C) ASM International (ASM) and The Minerals, Metals \& Materials Society (TMS) 2015

\section{INTRODUCTION}

THE Fe-Cu bimetallic alloy system is attractive for many applications due to its high strength and attractive electric and thermal properties. ${ }^{[1-5]}$ But similar to other metastable alloy systems, e.g., $\mathrm{Ni}-\mathrm{Ag}, \mathrm{Cu}-\mathrm{V}$, and $\mathrm{Co}-\mathrm{Cu}$, its synthesis suffers from the main drawback of limited miscibility of its components as solid solutions due to their positive energy of mixing (around $13 \mathrm{~kJ} / \mathrm{mol}$ for the $\mathrm{Fe}-\mathrm{Cu}$ system). ${ }^{[6,7]}$ Thus, they will not form intermetallic compounds and will have negligible mutual solid solubility in equilibrium at temperatures below $973 \mathrm{~K}\left(700^{\circ} \mathrm{C}\right) .{ }^{[8]}$ Many researchers have attempted to produce such alloys by rapid quenching, ${ }^{[9]}$ electrodeposition, ${ }^{[10,11]}$ and spinodal decomposition. ${ }^{[12]}$ One effective and easy method to synthesize the $\mathrm{Fe}-\mathrm{Cu}$ system with no conventional energy requirement in the form of applied heat or voltage is mechanical alloying (MA), which has the advantages of low-temperature processing, easy control of desired compositions, and the production of relatively large quantities of the compound. ${ }^{[6]}$ This method involves ball-milling powders of the pure constituents to obtain the sought solid solutions. In this process, the coherent lattices of the pure metals undergo simultaneous shear-induced deformation and thermal inter-diffusion, with the resulting composition being determined by the equilibrium between these two forces. ${ }^{[13]}$ There are many factors

ABDUL HAI ALAMI, Assistant Professor, and JEHAD ABED, MEERA ALMHEIRI, and AFRA ALKETBI, Research Assistants, are with the Sustainable and Renewable Energy Engineering Department, University of Sharjah, PO Box 27272, Sharjah, United Arab Emirates. Contact e-mail: aalalami@sharjah.ac.ae

Manuscript submitted September 23, 2015.

Article published online November 13, 2015 affecting this process, namely, milling time, milling temperature, post milling thermal processing, and alloy composition. ${ }^{[14,15]}$ Mechanical alloying results in a significant extension of mutual solubility of the elements relative to the equilibrium values, which can be observed through X-ray diffraction patterns. ${ }^{[16]}$ Depending on milling speed and orientation, milling operation is classified as either low-energy or high-energy, each provisioning certain operational advantages. For example, it was reported that low-energy ball milling of FCC and BCC metals leads to a refinement of the crystallite size to the nanometer scale. ${ }^{[17]}$ On the other hand, high-energy milling in planetary mills approximately provides desired results ten times faster than the low-energy process, which is important for technological and production-scale applications. It is generally reported, however, that the intensities of milling in the high- and low-energy mechanical alloying processes practically had no influence on the structure of the studied alloys. ${ }^{[18]}$ The produced alloys possess desirable mechanical and thermal properties, and most importantly here, microstructural properties that enhance their selective solar absorption properties. ${ }^{[19,20]}$ With a surface ionization potential (work function) difference $\left(\Delta E_{\mathrm{w}}\right)$ of around $0.43 \mathrm{eV}$, the $\mathrm{Fe}-\mathrm{Cu}$ alloy system have high intrinsic absorption coefficient that further optimizes its optical absorptance. ${ }^{[21]}$ Also, any observed roughness of the microstructure allows the interreflection of incident irradiation in the UV-Vis range that reduces reflection and scattering losses, ${ }^{[22]}$ and decreases the impedance between space and the absorber, which also leads to better absorbance properties. ${ }^{[23]}$

This work investigates a facile and economic process to synthesize a $\mathrm{Fe}-\mathrm{Cu}$ metastable alloy that would be suitable for enhancing solar absorption in the UV-VisNIR range for both thermal and photovoltaic 
applications. The synthesis of the alloy system is done through high-energy ball milling, which is an old, but effective mechanical alloying technique, and the resulting microstructure and optical absorptivity is analyzed and measured as milling time is increased. Also, the impedance of the compound is investigated using the four-probe technique.

\section{EXPERIMENTAL}

\section{A. Synthesis}

The synthesis by MA takes place in a Retsch PM 100 planetary ball mill in a $25 \mathrm{~mL}$ stainless steel grinding bowl to mechanically alloy a starting amount of $9 \mathrm{~g}$ of high purity copper $(<425 \mu \mathrm{m}, 99.5 \mathrm{pct})$ and iron $(<300 \mu \mathrm{m}, \geq 99 \mathrm{pct})$ powders, used as received from the supplier (Sigma-Aldrich). A target composition 50:50 of $\mathrm{Fe}-\mathrm{Cu}$ (weight percent) is used at a controlled milling speed of $600 \mathrm{rpm}$. Six $10-\mathrm{mm}$ stainless steel balls are used, making the filling ratio within the bowl 5:1. Milling is carried out for an hour at a time, pausing afterwards to cool the equipment and take a few milligrams of the powder for further characterization and testing. The run is to be terminated once microstructural changes become small, which in the present case took place after 6 hours.

\section{B. Microstructural Analysis via SEM-EDS and XRD}

The powder X-ray diffraction (XRD) patterns, plotted for five powder samples collected at a 2-hour interval for 8 hours, provide an insight into extent and progress of crystallization and the composition and grain structure of the developing solid solution. The X-ray patterns are recorded in the $2 \theta$ geometry between 40 and 90 deg at $0.02 \mathrm{deg} 2 \theta \mathrm{s}^{-1}$ with a Bruker D8 Advance DaVinci multipurpose $\mathrm{X}$-ray diffractometer with $\mathrm{Cu} \mathrm{K} \alpha$ radiation operating at $\lambda=1.5406 \AA$, $40 \mathrm{kV}$ tube voltage and $40 \mathrm{~mA}$ current. The microstructural results are used to calculate important quantities such as the lattice parameter from Cohen's method, grain size by the Full-width half-max (FWHM) analysis with the Scherrer's and Bragg's formulas. Fused pieces of the material collected after 6 hours milling time are examined under a scanning electron microscope (SEM) and the coupled energy dispersive X-ray spectrometer (EDS). The SEM is a VEGA3 XM by TESCAN, operating at $5 \mathrm{kV}$, while the EDS analysis is conducted with both map and point modes at the same operating voltage; the former was acquired during 3 minutes while the latter was from four different spots of the sample during 30 seconds live time.

\section{Thermal Analysis}

Differential Scanning Calorimetry (DSC) is performed on the milled powders to provide insight on the energy of formation and mixing of the resulting alloy. The stability of these alloys is due to the balance between the effectiveness of the MA process and thermal decomposition at high temperatures. For an endothermic reaction, heat flow indicates the phase shift within the solid solution (a peritectoid reaction). The calorimeter used is a Q20 from TA Instruments, running on $120 V_{\text {ac }}, 47$ to $63 \mathrm{~Hz}, 500 \mathrm{~W}(4.5 \mathrm{~A})$ and equipped with a liquid nitrogen cooling system (LNCS) that allows automatic and continuous temperature control within a full range of $93 \mathrm{~K}$ to $823 \mathrm{~K}\left(-180{ }^{\circ} \mathrm{C}\right.$ to $550{ }^{\circ} \mathrm{C}$ ). A few milligrams of as-is and 2, 4, 6, and 8 hours powders are encapsulated in an aluminum pan, and an empty reference pan sit on a thermoelectric disk surrounded by a furnace. As the temperature of the furnace is changed, heat is transferred to the sample and reference through the thermoelectric disk. The differential heat flow to the sample and reference is measured by area thermocouples. The phase formation, total enthalpy and heat flow through $273 \mathrm{~K}$ to $773 \mathrm{~K}\left(0{ }^{\circ} \mathrm{C}\right.$ to $500{ }^{\circ} \mathrm{C}$ ) temperatures are examined for the current test.

\section{Optical (Spectroscopic) Analysis}

Spectral measurements of absorption in the ultraviolet, visible, and near-infrared (UV-Vis-NIR) regions were carried out on all the powders (as-is and 2, 4, 6, and 8 hours milling time) with an Ocean Optics HR2000 high-resolution spectrometer. The HR2000 has a 300 lines per $\mathrm{mm}$ diffraction grating, $10 \mu \mathrm{m}$ entrance slit, a Sony ILX511 2048-Pixel element linear CCD array detector, and is operating in the effective wavelengths range 300 to $1100 \mathrm{~nm}$. The spectrometer is connected to a fiber optic reflection probe R200-7-SR, 2-m long, and of a $200-\mu \mathrm{m}$-core diameter. The reflection probe consists of a tight bundle of 7 optical fibers in a stainless steel ferrule with 6 illuminating fibers around one axial read fiber, fixed at $\sim 4 \mathrm{~mm}$ from the sample where losses due to scattering is assumed to be negligible, and all diffuse reflectance is collected at the probe. The source end of the reflection probe is connected to a tungsten halogen light source (Ocean Optics LS-1-LL). A reference surface in the form of a reflection standard (B0071519) is used to store baseline absorptance $(0 \mathrm{pct})$ spectra to facilitate comparison between the various alloy compositions. The integration time was set to $30 \mathrm{~ms}$ to contain the intensity of the highest acquired peak. The recorded time-resolved spectra were averaged over 10 readings to increase the signal-to-noise ratio.

\section{E. Electrical Impedance}

The impedance of the resulting $\mathrm{Fe}-\mathrm{Cu}$ compound is investigated by virtue of the four-probe method impedance spectroscopy. The four probes, arranged as seen in Figure 1, cover an area of $2 \mathrm{~cm}^{2}$ and are connected to a Biologic VSP-300 potentiostat, providing impedance spectroscopy $(10 \mu \mathrm{Hz}$ to $7 \mathrm{MHz}) \pm 12 \mathrm{~V}$ compliance, an automatic current range from $1 \mu \mathrm{A}$ up to $500 \mathrm{~mA}$ (7 decades) and a potential resolution down to $750 \mathrm{nV}$. Impedance parameters were determined by fitting of impedance spectra using Z-view software and generating the pertinent Nyquist plot. The $\mathrm{Fe}-\mathrm{Cu}$ alloy was deposited on a glass substrate by spreading an emulsion of $\mathrm{Fe}-\mathrm{Cu}$ in glycol and subsequently sintering 
the setup at $673 \mathrm{~K}\left(400{ }^{\circ} \mathrm{C}\right)$ for 30 minutes. It is noted that no phase change was observed afterwards in the post-sintered XRD results.

\section{RESULTS AND DISCUSSION}

\section{A. SEM and EDS}

The SEM micrograph of the $\mathrm{Fe}-\mathrm{Cu}$ system is shown in Figure 2(a) for a few milligrams removed after 6 hours of milling. There is obvious presence of various phases caused by the inter-diffusion of $\mathrm{Fe}$ and $\mathrm{Cu}$ results in different grain size distribution from a few nanometers to around $100 \mathrm{~nm}$. Upon further magnification, Figure 2(b) shows a homogeneous structure with the apparent shearing effect from milling, which produces a lamellar structure. ${ }^{[24]}$ An EDS analysis at two points (1) and (2) indicated on the figure shows a composition of 53 pct $\mathrm{Fe}$ and 47 pct $\mathrm{Cu}$ (weight percent) as evidence of successful inter-diffusion. This is in contrast to other synthesis methods involving casting, ${ }^{[4]}$ deposition, or

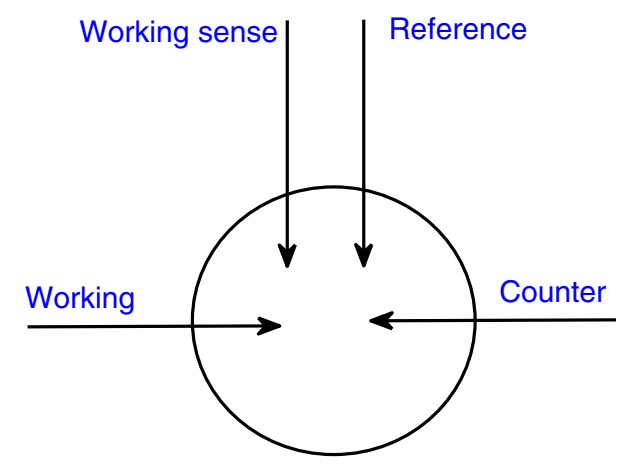

Fig. 1-Four-electrode arrangement for impedance spectroscopy. electron-beam forming that reported severely segregated phases when the alloy is cooled below $973 \mathrm{~K}\left(700^{\circ} \mathrm{C}\right)$.

The lattice strain energy $\Delta U_{\text {strain }}$ can be calculated from the relation $U_{\text {strain }}=(\bar{E} \delta)(2 \bar{r})^{2} \bar{d}$, where $\bar{E}$ is the average Young modulus for $\mathrm{Cu}$ and $\mathrm{Fe}, \bar{d}$ the average displacement of atoms $(\bar{d}=\delta \bar{r})$ and lattice distortion, $\delta$, is calculated using the equation $\delta=\mid \sum_{i=1}^{n} X_{i}\left(1-\frac{r_{i}}{\bar{r}}\right)^{2}$, where $X_{i}$ is the fraction of the $i$ th component ( $n$ here equals 2) and $r_{i}$ and $\bar{r}$ are the $i$ th and the average atom radii, respectively. ${ }^{[24]}$ The lattice distortion energy is found to be $8.61 \mathrm{~kJ} / \mathrm{mol}$. This value is one order of magnitude higher compared to the martensitic transformation in iron system (around $751 \mathrm{~J} / \mathrm{mol}$ ) that will form a homogenous single martensite phase with high density of lattice defect due to the pronounced amounts of microstrains found in all mechanically alloyed powders. ${ }^{[25]}$

\section{B. $X R D$}

The result of XRD analysis is shown in Figure 3 for the as-is and 2, 4, 6, and 8 hours milling time, to follow the evolution of the crystal structure. The as-is patterns show intense sharp peaks of elemental iron and copper are slightly shifted towards lower angles, which are consistent with the similar atomic sizes of $\mathrm{Fe}$ and $\mathrm{Cu}$ present in the same mixture, ${ }^{[7]}$ and the recorded signals are strong with little noise. It is interesting to observe these peaks widening and shifting further as milling proceeds due to the inter-diffusion of $\mathrm{Fe}$ and $\mathrm{Cu}$ atoms caused by the shearing action and the friction-induced temperature increase, promoting larger grain sizes. After 6 hours, a single phase is observed in which $\mathrm{Fe}$ atoms are diffused in the $\mathrm{Cu}$ matrix, or an $\mathrm{FCC} \mathrm{Cu}(\mathrm{Fe})$ solid solution. These results are also consistent with previous

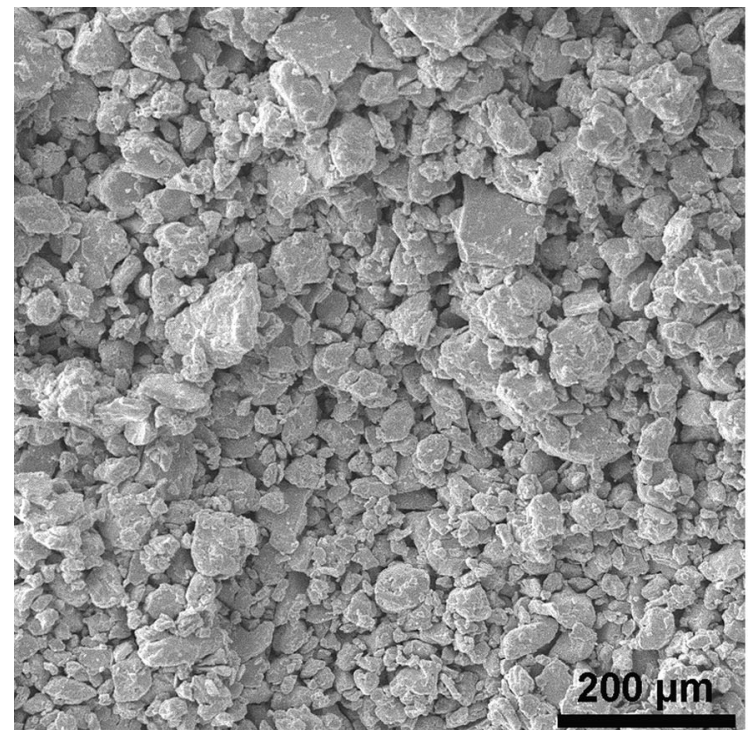

(a)

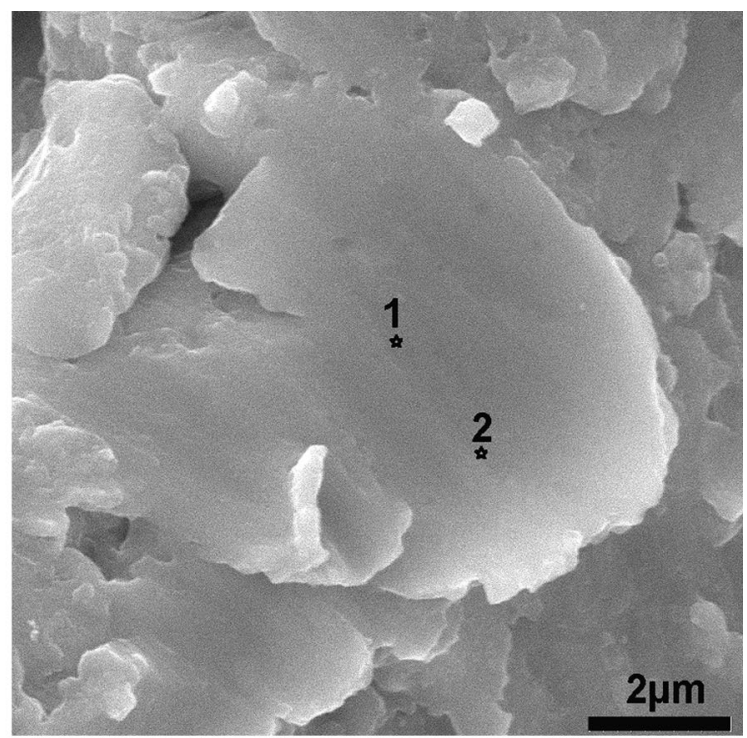

(b)

Fig. 2-SEM photomicrographs of the resulting microstructure at (a) 250 times magnification, showing the granular microstructure, and (b) 20k times magnification, showing homogeneous phases of $\mathrm{Fe}$ and $\mathrm{Cu}$, with EDS test locations indicated at 1 and 2. 


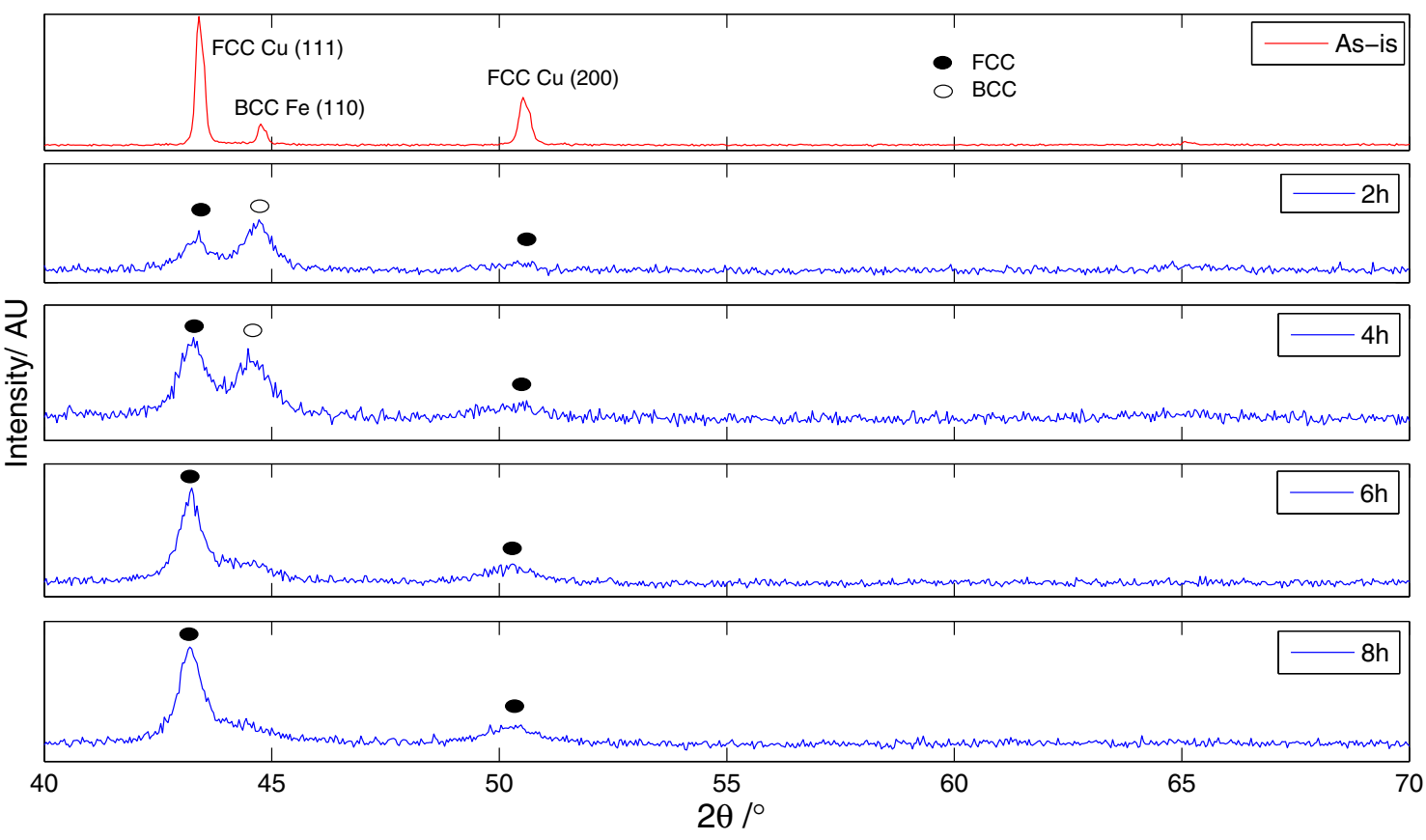

Fig. 3-XRD plots for progression of milling times.

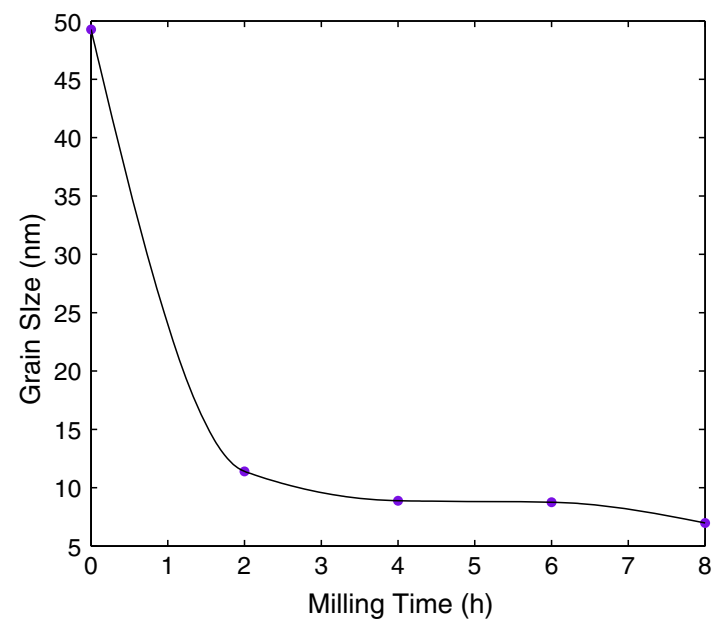

(a)

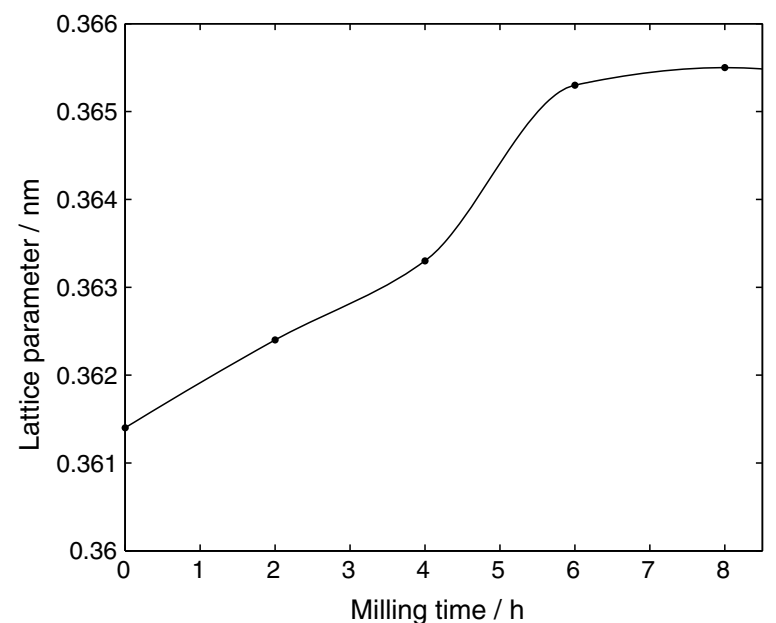

(b)

Fig. 4 - (a) Grain size variation with milling time, $(b)$ lattice parameter change with milling time.

reports ${ }^{[7,26]}$ and indicate the successful formation of the desired homogenous compound.

The grain size change with milling time is depicted in Figure 4(a) calculated from Bragg's law and Scherrer formula. It is noted from the figure that the grain size decreases rapidly as milling time increases, then it almost plateaus around 4 to 8 hours, which is consistent with trends reported elsewhere. ${ }^{[27]}$ The lattice parameter, however, shows a steady increase with milling time as $\mathrm{Fe}$ diffusion continues into $\mathrm{Cu}$ up until 6 hours, after which the diffusion levels off as seen in Figure 4(b).

\section{Thermal Analysis Results}

The results obtained from the DSC are shown in Figure 5 for all milling times and also for the as-is specimen. The results for 6 and 8 hours show the least difference between the obtained peaks, indicating a limiting time for the milling process, which can be correlated with the XRD patterns of Figure 3. The results are inverted to show a positive scale and are inline with those found in previous work. ${ }^{[20]}$ The peaks also occur at successively higher temperature, indicating the release of the stored strain energy from the 


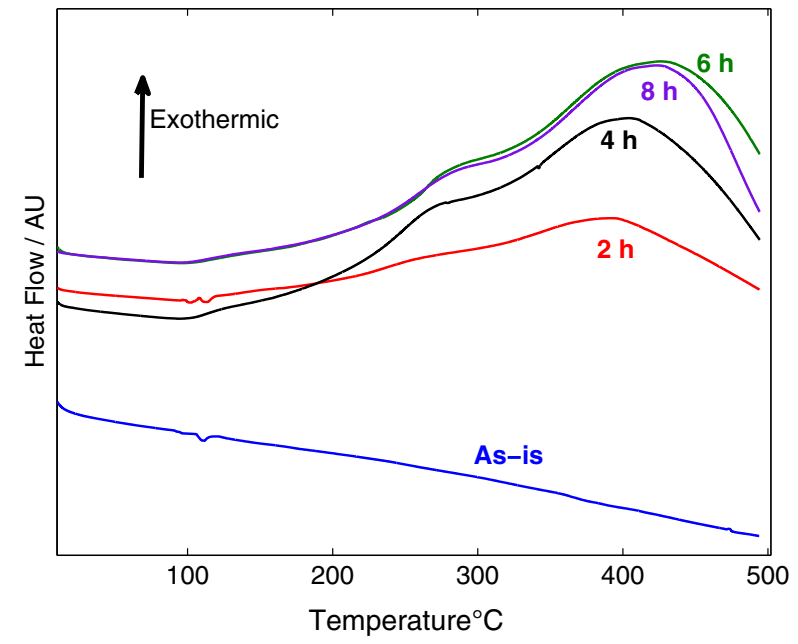

Fig. 5-Differential scanning calorimetry heat flow plots vs milling times.

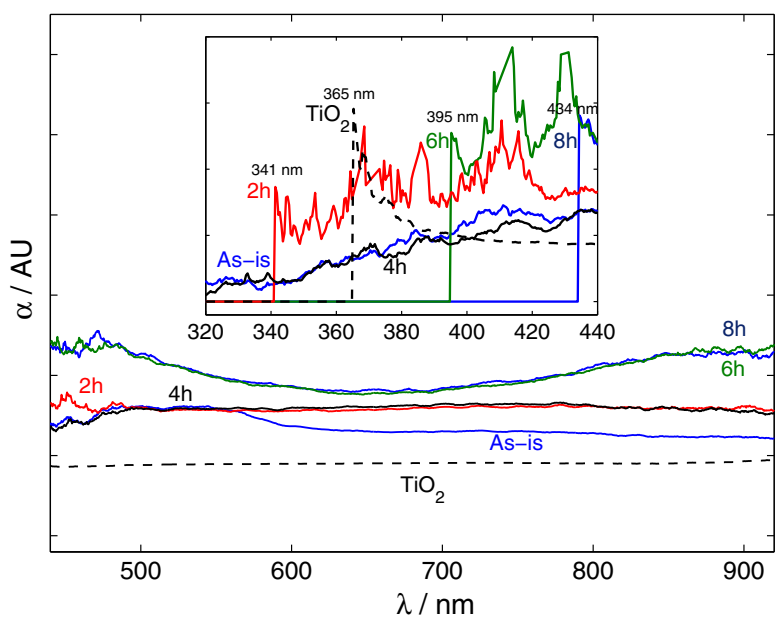

Fig. 6-Absorptivity results at different milling times with $\mathrm{TiO}_{2}$ superimposed in dotted line.

high-energy ball milling. Although the heat flow $(\Delta \mathrm{H})$ depicted in Figure 5 adequately approximates Gibbs free energy $(\Delta G)$ required for phase dissociation, it is the latter that determines the thermodynamic stability of solid phases at constant temperatures. This finding is consistent with ones reported by $\mathrm{Ma}$ and Matshimo ${ }^{[6]}$ who concluded that the FCC phase would be more stable than its BCC counterpart throughout the composition range up to $80 \mathrm{pct} F \mathrm{Fe}$.

\section{Spectroscopy}

The evolution of the microstructure with milling has impacted the optical absorptivity of the alloy, as can be seen in Figure 6. The original powder shows a slight increase in absorptivity with respect to the mirror reference up to $500 \mathrm{~nm}$, at which it plateaus until $550 \mathrm{~nm}$, after which absorptivity decreases asymptotically towards $900 \mathrm{~nm}$. As for milling times of 2, 6, and
8 hours, the onset of absorptivity is seen to be an abrupt step increase at progressive wavelengths of 341,396 , and $434 \mathrm{~nm}$, respectively. Another interesting observation from the curves can be made in conjunction with the XRD plots of Figure 3 for the 2 to 4 hours on one hand and 6 to 8 hours alloys on the other. The former set shows a virtually constant absorptivity across the tested wavelength of Vis-NIR (450 to $900 \mathrm{~nm}$ ) due to the existence of both FCC and BCC structures, while the latter starts with a high onset value, then assumes a flat parabolic shape with an apex at $650 \mathrm{~nm}$, thought to be due to an all-FCC microstructure. Longer milling times of 6 and 8 hours, exhibit a 63 and 81 pct, enhanced absorptivity, respectively, compared to as-is powder if the areas under the absorptivity curves are integrated from 450 to $900 \mathrm{~nm}$. This enhancement is due in part to the roughness in microstructure that augments the probability of absorbing the diffracted and trapped light beams by adjacent grains. Roos et al. ${ }^{[28-31]}$ have reported similar trends of optical properties of copper oxide thin films prepared by thermal and chemical oxidations and plotted against processing time, and the results are in general agreement of what is reported in this work.

It is also useful to compare the obtained optical properties of the prepared compounds against $\mathrm{TiO}_{2}$, a known photo catalyst that is used extensively in dye-sensitized solar cells (DSSCs). Thus, the optical absorptivity in the UV-Vis-NIR (280 to $900 \mathrm{~nm}$ ) range was measured for an as-received $\mathrm{TiO}_{2}$ powder (Sigma-Aldrich) and shown as a dashed line in Figure 6. The curve shows a standard optical characteristics of the $\mathrm{TiO}_{2}$ powder as reported in literature, ${ }^{[31]}$ where negligible absorptivity below $365 \mathrm{~nm}$ is replaced with a sharp increase of absorptivity followed by an exponential decay right before the $400 \mathrm{~nm}$ mark where it levels off as Figure 6 depicts. The advantage of using the suggested mesoporous $\mathrm{Fe}-\mathrm{Cu}$ alloy is thus two-fold, one is in the tuning of absorption response to higher wavelengths that can be well defended in situations where target solar cells are to be operated indoors or at different incident radiation intensities, and the other benefit is the obvious enhanced absorptivity magnitudes over the rest of the Vis-NIR spectrum which has many benefits for both solar thermal and solar photovoltaic applications.

\section{E. Electrical Impedance}

The electrical impedance of a thin film of an 8 hours milled $\mathrm{Fe}-\mathrm{Cu}$, deposited on a glass substrate is shown in the Nyquist plot of Figure 7.

Compared with the near zero real impedance of the as-is starting powder, the 8 hours milling time displayed a large impedance value (around 120 $\Omega$ ) suggesting a fundamental change in the electric behavior due to the new composition, akin to the thermal conductivity of an alloy being substantially less than that of its pure components. This result is important, especially that oxidation is not observed in the EDS analysis of the components, which clearly indicates a semi-conductive behavior of the resulting alloy that paves the way of using the $\mathrm{Fe}-\mathrm{Cu}$ compound as a photocatalyst in solar 


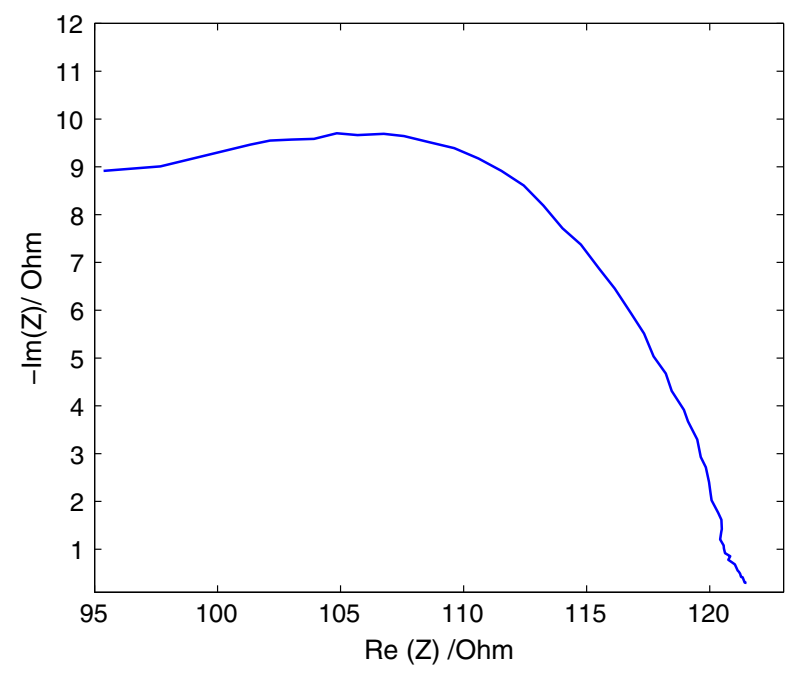

Fig. 7-Impedance spectroscopy of $8 \mathrm{~h}$ milled $\mathrm{Fe}-\mathrm{Cu}$.

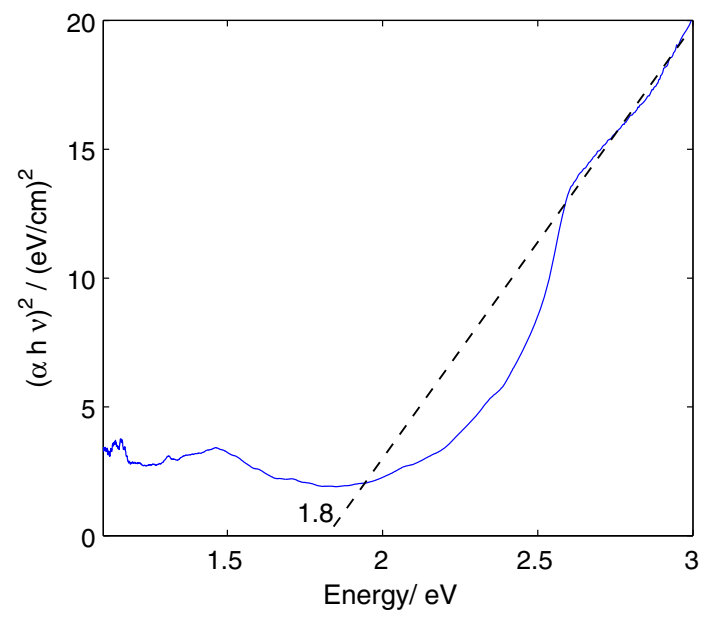

Fig. 8-Energy bandgap of the resulting $\mathrm{Fe}-\mathrm{Cu}$ compound.

cells, especially organic and dye-sensitized ones to replace the more common titania that showed inferior absorptivity in the useful solar spectrum as seen in Figure 6. Since the $\mathrm{Fe}-\mathrm{Cu}$ compound exhibits this semi-conductive behavior, an estimation of the resulting bandgap is shown in Figure 8. The band gap is determined from the traditional Tauc relationship; $\alpha \cdot h v=A \cdot\left(h \cdot v-E_{\mathrm{g}}\right)^{n}$, by plotting $(\alpha \cdot h \cdot v)^{1 / n} v s$ the photoenergy $h \cdot v$, where $\alpha$ is the absorption coefficient, $A$ is the edge width parameter, $E_{\mathrm{g}}$ is the optical band gap value and $n$ is a constant dependent on the nature of the transition $(n=1 / 2$ for a direct allowed transition and 2 for an indirect transition). ${ }^{[29,30]}$ An extrapolation of the linear region of the plot for the ordinate equals to zero, gives an absorption edge energy that corresponds to the value of the optical band gap $E_{\mathrm{g}}$. With $n$ being $1 / 2$ for best fitting, the results in Figure 8 indicate the bandgap value for in $\mathrm{Cu}-\mathrm{Fe}$ alloys with milling times over 6 hours. According to the figure, band gap results start to appear after 6 hours of milling as elements diffusion becomes pronounced and the microstructure shifts to metastability, which is also inferred from the XRD plots of Figure 3. The obtained optical band gap value is $1.8 \mathrm{eV}$ for milling times 6 and 8 hours.

\section{CONCLUSION}

In this paper an economical and facile method for the production of a selective solar absorber material, made from $\mathrm{Fe}-\mathrm{Cu}$ metastable alloy system is investigated. High-energy ball milling, a mechanical alloying technique, was used to synthesize the alloy and the resulting microstructure was examined using SEM-EDS and XRD at 2 hours intervals starting from the as-is powder up to the final duration of 8 hours. The resulting alloy is a homogenous, FCC single phase of $\mathrm{Fe}$ diffused in $\mathrm{Cu}$ with no segregation of elements. The optical absorptivity in the Vis-NIR ranges for the alloy was measured for the same durations and the results show a strong correlation between the microstructural morphology and the optical behavior and enhancement of spectral absorptivity between 400 and $900 \mathrm{~nm}$. The spectral absorptivity is enhanced up to 81 pct for the 8 hours milled alloy compared to the original powder. The produced alloy can be applied to a variety of substrates of solar absorbers to enhance solar absorption, which an attractive feature given the intrinsic desirable mechanical properties of hardness and strength and low specific heat. The increase in the impedance of up to $120 \Omega$ is an indication of the fundamental change of electrical properties of the resulting compound after 8 hours of milling, making it a good candidate for dye-sensitized solar cell applications as a porous photocatalyst, with a tunable bangap values and desirable nano-scale grain size.

\section{ACKNOWLEDGMENTS}

The authors would like to acknowledge the assistance and contribution of X-ray Center for Material Analysis and the Chemistry laboratories at the University of Sharjah.

\section{REFERENCES}

1. M. Hasebe and T. Nishizawa: CALPHAD, 1981, vol. 5, pp. 10508.

2. X. Huang and T. Mashimo: J. Alloys Compd., 1999, vol. 288, pp. 299-305.

3. A.W. Weeber: J. Phys. F Met. Phys., 1987, vol. 17, pp. 809-13.

4. J. He, J.Z. Zhao, and L. Ratke: Acta Mater., 2006, vol. 54, pp. $1749-57$.

5. G. Mazzone and M.V. Antisari: Phys. Rev. B, 1996, vol. 54, pp. 441-46.

6. E. Ma, M. Atzmon, and F.E. Pinkerton: J. Appl. Phys., 1993, vol. 74 , p. 955 .

7. J. Xu, U. Herr, T. Klassen, and R.S. Averback: J. Appl. Phys., 1996, vol. 79, p. 3935.

8. M. Hansen and K. Anderko: Constitution of Binary Alloys, 2nd ed., McGraw-Hill Book Co., New York, 1965. 
9. I. Lyasotsky, N. Dyakonova, D. Dyakonov, and E. Vlasova: Rev. Adv. Mater. Sci., 2008, vol. 18, pp. 695-702.

10. G. Fu, Z. Hu, L. Xie, X. Jin, Y. Xie, Y. Wang, Z. Zhang, Y. Yang, and H. Wu: Int. J. Electrochem. Sci., 2009, vol. 4, pp. 1052-62.

11. R.K. Gupta, N.L. Sukiman, M.K. Cavanaugh, B.R.W. Hinton, C.R. Hutchinson, and N. Birbilis: Electrochim. Acta, 2012, vol. 66, pp. 245-54.

12. Q. Li: Sci. China Ser. E-Technol. Sci., 2009, vol. 52, pp. 1919-22.

13. N. Das, J. Mittra, B.S. Murty, S.K. Pabi, U.D. Kulkarni, and G.K. Dey: J. Alloys Compd., 2013, vol. 550, pp. 483-95.

14. M. Greenfield and C. Pierce: Weld. J., 1973, vol. 52, pp. 524-27.

15. C. Ravi, C. Wolverton, and V. Ozolinš: Europhys. Lett. (EPL), 2006, vol. 73, pp. 719-25.

16. J. Xu, G.S. Collins, L.S.J. Peng, and M. Atzmon: Acta Mater., 1999, vol. 47, pp. 1241-53.

17. D. Oleszak and P.H. Shingu: J. Appl. Phys., 1996, vol. 79, pp. $2975-80$.

18. E. Jartych, J.K. Żurawicz, D. Oleszak, and M. Pękaa: J. Magn. Magn. Mater., 2000, vol. 208, pp. 221-30.

19. J. Roeder, J. Sculac, and M. Notis: Microbeam Anal., 1984 , vol. 243, p. 292.

20. Y.-Y. Chuang, R. Schmid, and Y.A. Chang: Metall. Trans. A, 1984, vol. 15, pp. 1921-30.
21. C.E. Kennedy: Review of Physical Vapor Deposited (PVD) Spectrally Selective Coatings for Mid- and High-Temperature Solar Thermal Applications. National Renewable Energy Laboratory, Colorado, 2002.

22. A.H. Alami, A. Allagui, and H. Alawadhi: Renew. Energy, 2015, vol. 82, pp. 21-25.

23. E. Rephaeli and S. Fan: Appl. Phys. Lett., 2008, vol. 92, p. 211107.

24. Y. Zhang, Y.J. Zhou, J.P. Lin, G.L. Chen, and P.K. Liaw: $A d v$. Eng. Mater., 2008, vol. 10, pp. 534-38.

25. S. Takaki and K. Fukunaga: J Syarif Mater. Trans., 2004, vol. 45, pp. $2245-51$.

26. E. Gaffet, M. Harmelin, and F. Faudot: J. Alloys Compd., 1993, vol. 194, pp. 23-30.

27. F. Lucas, B. Trindade, B. Costa, and G. Le Caër: J. Metastab. Nanocryst. Mater., 2003, vol. 18, pp. 49-56.

28. A. Roos, T. Chibuye, and B. Karlsson: Solar Energy Mater., 1983, vol. 7, pp. 453-65.

29. J. Tauc, R. Grigorovici, and A. Vancu: Phys. Status Solidi B, 1966, vol. 15 , pp. 627-37.

30. I.Y. Erdogan and O. Gullu: J. Alloys Compd., 2010, vol. 492 (1-2), pp. $378-83$.

31. C. Kormann: J. Phys. Chem., 1988, vol. 92, pp. 5196-201. 